\title{
DETECÇ̃̃O DE TRYPANOSOMA VIVAX POR DIFERENTES TÉCNICAS DE DIAGNÓSTICO PARASITOLÓGICO REALIZADAS À CAMPO
}

\author{
DETECTION OF TRYPANOSOMA VIVAX IN FOUR DISTINCT \\ DIRECT TESTS
}

\author{
T. S. A. BASTOS ${ }^{*}$, D. M. C. MADRID ${ }^{1}$, A. M. FARIA ${ }^{1}$, L. C. BESSA ${ }^{1}$, A. M. SOUZA ${ }^{1}$, \\ G. F. C. LINHARES ${ }^{1}$
}

\begin{abstract}
RESUMO
Tripanossomose é uma doença causada por protozoário hemoparasita que assume cada vez maior importância econômica no país, sobretudo por ocasionar queda de desempenho produtivo em bovinos, aumento de taxa de aborto e mortalidade. O parasito pode ser transmitido aos animais através da picada da mosca Tsé-Tsé ou por meios iatrogênicos como utilização de mesma agulha para múltiplos animais. Durante surto da doença em propriedade de produção leiteira no estado de Goiás, foram realizadas quatro técnicas de diagnóstico parasitológico direto para detecção de animais parasitados por Trypanosoma vivax. Os resultados foram comparados para permitir a escolha da melhor técnica a ser empregada a campo. O surto ocorreu em uma propriedade rural com aproximadamente 700 animais no rebanho, localizada próximo ao município de Bonfinópolis - GO. Foram colidas ao acaso 300 amostras de sangue venoso de animais da raça girolando. Todo o material foi processado e analisado na propriedade. Todas as amostras foram submetidas à pesquisa direta do hemoparasito em: gota de sangue montada entre lâmina $\mathrm{e}$ lamínula; lâminas com extensão sanguínea coradas com Giemsa; Técnica de Woo; e pesquisa em creme leucocitário obtido após centrifugação em tubos de microhematócrito. Na pesquisa em creme leucocitário foram detectados 19 animais parasitados. Durante o exame parasitológico direto de gota de sangue montado entre lâmina e lamínula foram detectados 18 animais parasitados. Pela Técnica de Woo, detectou-se 26 animais parasitados. Por último, na extensão sanguínea coradas com Giemsa observou-se 12 animais positivos. Concluiu-se que a melhor técnica para diagnóstico a campo de tripanossomose bovina foi a Técnica de Woo. A partir dela, foram detectados proporcionalmente um quantitativo de 1,36x, 1,44x e 2,16x mais animais parasitados frente ao exame parasitológico direto de sangue montado entre lâmina e lamínula, pesquisa em extensão sanguínea coradas com Giemsa e pesquisa em creme leucocitário, respectivamente.
\end{abstract}

PALAVRAS-CHAVE: DIAGNÓSTICO. EPIDEMIOLOGIA. TRYPANOSSOMA.

ÁREA TEMÁTICA: Doenças Parasitárias 